\title{
S1 Thermodynamics
}

The driving forces $\left(-\Delta \mathrm{G}_{\mathrm{CR}}{ }^{\circ}[\mathrm{eV}]\right)$ for the intramolecular charge-recombination $(\mathrm{CR})^{\text {ref }}$ processes were calculated by applying equation $\mathrm{S} 1$ :

$$
-\Delta G_{\mathrm{CR}}^{\circ}=E_{1 / 2}\left(\mathrm{D}^{\bullet+} / \mathrm{D}\right)-E_{1 / 2}\left(\mathrm{~A} / \mathrm{A}^{\bullet-}\right)+\Delta G_{\mathrm{S}}
$$

where $E_{1 / 2}^{\circ}\left(\mathrm{D}^{\bullet+} / \mathrm{D}\right)$ is the first one-electron oxidation potential of the oligomer donor moiety, while $E^{\circ}{ }_{1 / 2}\left(\mathrm{~A} / \mathrm{A}^{\bullet-}\right)$ refers to the first one-electron reduction potential of the $\mathrm{C}_{60}$ electron acceptor. In the next step we elucidate the role of the solvent $\left(\Delta \mathrm{G}_{\mathrm{S}}\right)$ on the relative energy of the charge-separated state by referring to the "Dielectric Continuum Model":

$$
\Delta G_{\mathrm{S}}=\frac{e^{2}}{4 \pi \varepsilon_{0}} \quad \frac{1}{2 R_{+}}+\frac{1}{2 R_{-}}-\frac{1}{R_{\mathrm{D}-\mathrm{A}}} \frac{1}{\varepsilon_{\mathrm{S}}}-\frac{1}{2 R_{+}}+\frac{1}{2 R_{-}} \frac{1}{\varepsilon_{\mathrm{R}}}
$$

Furthermore, the driving forces $\left(-\Delta \mathrm{G}_{\mathrm{CS}}{ }^{\circ}[\mathrm{eV}]\right)$ for the intramolecular chargeseparation (CS) processes were determined by:

$$
-\Delta G_{\mathrm{CS}}{ }^{\circ}=\Delta E_{0-0}-\left(-\Delta G_{\mathrm{CR}}\right)
$$

Hereby, $\Delta E_{0-0}$ is the energy of the 0-0 transition energy gap between the lowest excited state and the ground state. The accordingly calculated $-\Delta \mathrm{G}_{\mathrm{CS}}{ }^{\circ}$ and $-\Delta \mathrm{G}_{\mathrm{CR}}{ }^{\circ}$ values are given in Table 4.

Rehm, D.; Weller, A. Isr. J. Chem. 1970, 8, 529.

Weller, A. Z. Physik. Chem. 1982, 132, 93.

Gaines, G.L.I.; O'Neil, M.P.; Svec, W.A.; Niemczyk M.P.; Wasielewski, M.R. J. Am. Chem. Soc. 1991, 113, 719.

Kavarnos, G. J. Fundamentals of Photoinduced Electron Transfer, VCH-Wiley: New York, NY, 1993. 